\title{
Cost-effectiveness of human papillomavirus vaccination for prevention of cervical cancer in Taiwan
}

Pang-Hsiang Liu ${ }^{1,2}$, Fu-Chang Hu${ }^{1}$, Ping-Ing Lee ${ }^{3}$, Song-Nan Chow ${ }^{4}$, Chao-Wan Huang ${ }^{1}$, Jung-Der Wang ${ }^{1,2,5^{*}}$

\begin{abstract}
Background: Human papillomavirus (HPV) infection has been shown to be a major risk factor for cervical cancer. Vaccines against HPV-16 and HPV-18 are highly effective in preventing type-specific HPV infections and related cervical lesions. There is, however, limited data available describing the health and economic impacts of HPV vaccination in Taiwan. The objective of this study was to assess the cost-effectiveness of prophylactic HPV vaccination for the prevention of cervical cancer in Taiwan.

Methods: We developed a Markov model to compare the health and economic outcomes of vaccinating preadolescent girls (at the age of 12 years) for the prevention of cervical cancer with current practice, including cervical cytological screening. Data were synthesized from published papers or reports, and whenever possible, those specific to Taiwan were used. Sensitivity analyses were performed to account for important uncertainties and different vaccination scenarios.

Results: Under the assumption that the HPV vaccine could provide lifelong protection, the massive vaccination among preadolescent girls in Taiwan would lead to reduction in $73.3 \%$ of the total incident cervical cancer cases and would result in a life expectancy gain of 4.9 days or 8.7 quality-adjusted life days at a cost of US\$324 as compared to the current practice. The incremental cost-effectiveness ratio (ICER) was US\$23,939 per life year gained or US\$13,674 per quality-adjusted life year (QALY) gained given the discount rate of 3\%. Sensitivity analyses showed that this ICER would remain below US\$30,000 per QALY under most conditions, even when vaccine efficacy was suboptimal or when vaccine-induced immunity required booster shots every 13 years.

Conclusions: Although gains in life expectancy may be modest at the individual level, the results indicate that prophylactic HPV vaccination of preadolescent girls in Taiwan would result in substantial population benefits with a favorable cost-effectiveness ratio. Nevertheless, we should not overlook the urgency to improve the compliance rate of cervical screening, particularly for older individuals.
\end{abstract}

\section{Background}

Cervical cancer is one of the most common female malignancies worldwide. The cervical cancer rate has declined in Taiwan over the last decade, an effect largely attributed to widespread screening for cervical cancer. Nonetheless, the compliance with cervical screening in Taiwan remains suboptimal that the annual screening rate was $28.6 \%$ for women aged over 30 years [1], and the incidence of cervical cancer is consistently higher

\footnotetext{
* Correspondence: jdwang@ntu.edu.tw

${ }^{1}$ National Clinical Trial and Research Center, National Taiwan University
} Hospital, Taipei, Taiwan than those in neighboring countries [2]. In 2006, there was an annual incidence rate of 16.2 per 100,000 people for invasive cervical cancer and a mortality rate of 7.8 per 100,000 people in comparison with breast cancer incidence and mortality of 61.1 and 12.8 per 100,000 people, respectively [3].

Genital infection with human papillomavirus (HPV) has been well established to be the determining cause of cervical cancer $[4,5]$. Researchers reported the HPV prevalence in Taiwan was around 10-20\% [6-9]. While HPV comprises a wide range of genotypes, several types are defined as high-risk, or oncogenic, for their strong carcinogenicity. A primary preventive measure involving 
prophylactic vaccination against these oncogenic HPVs has thus been developed, and there are two vaccines that are currently available. One is the bivalent vaccine $[10,11]$, and the other is the quadrivalent vaccine [12], which commonly target the HPV-16 and HPV-18. Safety and satisfactory efficacy against type-specific HPV infection and related precancerous lesions have been demonstrated for both vaccines. Although their efficacy for preventing cervical cancer has not been comprehensively proven yet, it seems reasonable to expect such an outcome.

A number of studies have been conducted to evaluate the potential cost-effectiveness for prevention of cervical cancer through HPV vaccination, with a range of results [13-26]. Indeed, the cost-effectiveness of HPV vaccination varies between regions by many factors including different epidemiology of HPV infection and cervical screening efforts; Puig-Junoy and Lopez-Valcarcel reported that large variations existed in the cost-effectiveness results of different studies even for the same country [27]. Currently, there are still limited data evaluating the economic impact of cervical cancer vaccination in Taiwan $[28,29]$. The aim of this study was therefore to assess the cost-effectiveness of prophylactic HPV vaccination on the prevention of cervical cancer in Taiwan.

\section{Methods}

Decision model

We developed a Markov model [30] to assess the costeffectiveness of the prophylactic vaccine against highrisk HPV infections and related cervical cancers in Taiwan (Figure 1) using the TreeAge software (TreeAge Software, Inc., Williamstown, MA, USA). The perspective of analysis considered in this study was that of the healthcare payers. The target population for our analysis included all adolescent girls in Taiwan; the time horizon was lifetime.

Our model simulated the natural history of a hypothetical cohort of 12-year-old girls who were either administered the cervical cancer vaccine or who received the current standard of care from adolescence to death. For each strategy, the model incorporated probabilities of occurrence and progression of high-risk HPV, of squamous intraepithelial lesions (SIL) and of cervical cancer, as well as the probability of death, quality of life and costs associated with the corresponding health states. Every year, each person is at risk of developing high-risk HPV, SIL or cervical cancer. Over time, an infected woman's HPV infection can regress, persist or progress into SIL. High-grade SIL may possibly progress to cervical cancer. In addition to being at risk for death caused by cervical cancer, all women are still at risk for agespecific death that is unrelated to cervical cancer.
We assumed that girls with and without vaccination would receive the same standard of care that is currently being implemented, which includes routine papanicolaou (Pap) tests for compliant women every year starting from 30 years of age. At each screening event, cervical lesions are detected based on the sensitivity of the screening test $[31,32]$. Follow-up and/or treatment will take place depending on the type of detected lesion with a certain probability of success.

\section{Model parameters and base case assumptions}

Transition probabilities for the hypothetical cohort from one clinical state to another over time were derived from published papers, reports or expert opinions. Whenever possible, data specific to Taiwan were used. Detailed information is provided in Table 1 which depicts the base case value, range for sensitivity analysis and data source for input parameters. The base case value represents our best estimate for each variable.

\section{HPV infection}

The natural history of HPV infection is complex, and clearance or persistence of infection, together with progression to SIL, differ depending on the genotype of HPV, patient characteristics and study design. To simplify the procedure, we only classified the HPV genotypes into high- and low-risk. Our age-specific estimates for incidence, progression and regression were averages for all types of oncogenic HPV (such as HPV-16, 18, 31, $33,35,39,45,51,52,53,56,58,59,68$ and 70) based on the population prevalence data [6-9]. In our base case analysis, the annual incidence infection began at age 15, peaked at age 20 and dropped off after age 35 . Given HPV infection, regression rates were highest for women $<25$ years $(46 \% / y r)$ and lowest for women $>50$ years $(3 \% / \mathrm{yr})$, reflecting an observation of more persistent infections in the older age group [33-38].

\section{Cervical cancer}

In the model calibration process, the transition probabilities for progression from high-risk HPV infection to low-grade SIL, from low-grade to high-grade SIL and from high-grade SIL to cervical cancer varied within valid ranges derived from published papers to fit the model-predicted incidence rates of cervical cancer with data taken from the National Cancer Registry of Taiwan

The probability of diagnosing asymptomatic cervical lesions is a function of a woman's likelihood of receiving a cervical screening and on the sensitivity and specificity of this test $[31,32]$. The Taiwanese government launched a nationwide cervical screening program in July of 1995, in which annual Pap smear screenings were offered to women aged over 30 years. According to current reports in Taiwan, the annual compliance rate for Pap testing is approximately $30 \%$ by age 60 , which proportionately declines to $15 \%$ at age 70 or older $[1,39]$. 


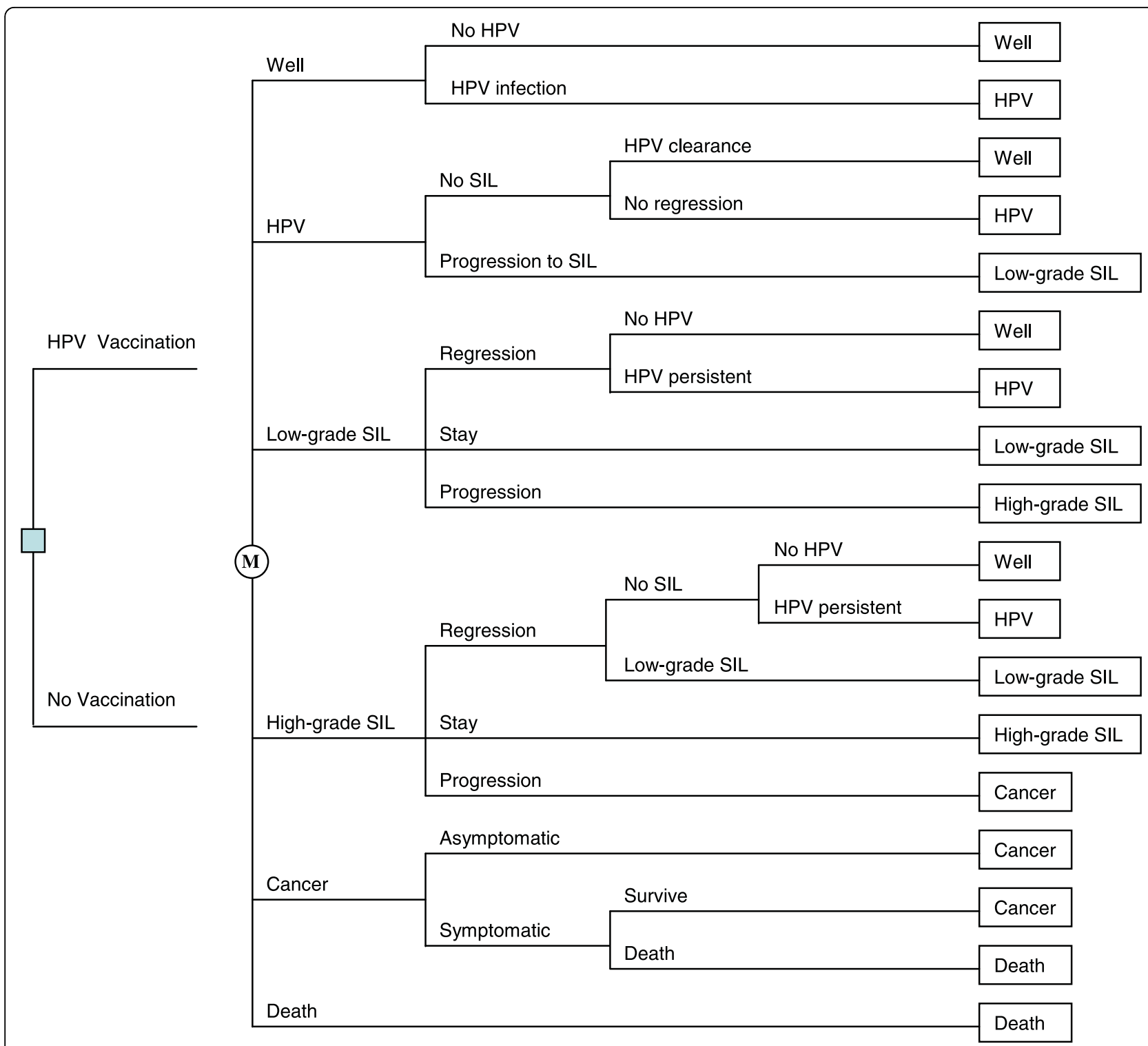

Figure 1 The Markov decision model. The square on the left represents the prophylactic vaccination decision. Each woman's health is tracked by a Markov model after entering the Markov tree (denoted by circles containing an alphabet ' $M$ '). In each cycle, women are at risk of developing oncogenic human papillomavirus (HPV) infection, SIL (squamous intraepithelial lesions), cervical cancer or mortality. The Markov tree branches with ends of rectangles represent the above clinical events that can occur during each 1-year period as a 12-year-old girl is followed until death.

The National Cancer Registry of Taiwan provided us with the average survival function of invasive cervical cancer, which does not differentiate at different clinical stages. From 1990 to 2005, the registry collected a total of 39,470 cases, which were linked with our National Mortality Registry between 1990 and 2007 to determine if the patient was still alive. These follow-up data provided us with detailed survival rates up to 18 years and were used in this simulation, and if a patient survived more than 15 years, we assumed that she was in a remission state and would not die of cervical cancer.

\section{Quality of life}

Utilities are a measure of the quality of life rated on a scale from 0 to 1 , where 0 represents death and 1 represents ideal health. Undiagnosed HPV infection and cervical lesions were considered to be asymptomatic with no decrease in utility. Diagnosed low- and high-grade SIL were assigned a lower utility (namely, 0.97) for a 1 -year duration [40]. Oncogenic HPV infection can remarkably affect the quality of life for a woman with cervical cancer. For invasive cervical carcinoma, a woman's utility was assumed to reduce down to 0.70 
Table 1 Input parameters and sources*

\begin{tabular}{|c|c|c|c|}
\hline Parameters & $\begin{array}{l}\text { Base case } \\
\text { value }\end{array}$ & $\begin{array}{l}\text { Range for sensitivity } \\
\text { analysis }\end{array}$ & Data source \\
\hline \multicolumn{4}{|l|}{ Vaccine variables } \\
\hline Vaccine efficacy, \% & 75 & $50-100$ & {$[10,12,46-48]$} \\
\hline Vaccine coverage, $\%$ & 100 & $30-100$ & Assumed \\
\hline Age for starting vaccination, year & 12 & $12-36$ & {$[49]$} \\
\hline Immunity duration, year & lifetime & 10-lifetime & {$[46,47]$} \\
\hline Booster shot compliance, $\%$ & 70 & $30-100$ & Assumed \\
\hline \multicolumn{4}{|l|}{ Screening variables } \\
\hline Age for starting cervical screening, year & 30 & & {$[1,39]$} \\
\hline Screening interval, year & 1 & $1-5$ & {$[1,39]$} \\
\hline Screening compliance, \% & $15-30$ & $0-70$ & {$[1,39]$} \\
\hline Pap test sensitivity for SIL & 0.60 & $0.40-0.80$ & {$[31,32]$} \\
\hline Pap test specificity for SIL & 0.97 & $0.95-0.98$ & {$[31,32]$} \\
\hline \multicolumn{4}{|l|}{ Costs, US\$ } \\
\hline Vaccine cost (3 doses) & 364 & 273-455 & Assumed \\
\hline Booster shot cost & 121 & $91-152$ & Assumed \\
\hline Cost of Pap test & 16 & $12-20$ & {$[41]$} \\
\hline Cost for a false-positive SIL & 66 & $50-83$ & {$[41]$} \\
\hline Cost of treatment for cervical cancer & 10000 & $7500-12500$ & [41] \\
\hline Cost of treatment for high-grade SIL & 245 & 183-306 & [41] \\
\hline \multicolumn{4}{|l|}{ Utilities } \\
\hline Normal population & 1 & & Assumed \\
\hline Diagnosed SIL for 1-year & 0.97 & $0.80-1$ & {$[13,40]$} \\
\hline Cervical cancer & 0.70 & $0.25-1$ & Assumed \\
\hline Cervical cancer, follow-up & 0.95 & $0.90-1$ & Assumed \\
\hline \multicolumn{4}{|l|}{ Transition probabilities } \\
\hline Incidence of high-risk HPV infection & $0-0.09$ & $0.5-2 \times$ base case & {$[6-9]$} \\
\hline HPV infection resolving & $0.03-0.46$ & $0.67-1.5 \times$ base case & {$[33-38]$} \\
\hline Developing low-grade SIL from high-risk HPV infection & 0.065 & $0.05-0.08$ & {$[50-59]$} \\
\hline Low-grade SIL regressing & $0.027-0.142$ & $0.67-1.5 \times$ base case & {$[13,54-58,60]$} \\
\hline $\begin{array}{l}\text { Low-grade SIL regressing to previous HPV infection state, given } \\
\text { regression occurs }\end{array}$ & 0.10 & $0-0.20$ & {$[13,54]$} \\
\hline Developing high-grade SIL from low-grade SIL & $0.005-0.400$ & $0.67-1.5 \times$ base case & {$[50-58]$} \\
\hline High-grade SIL regressing & $0.037-0.058$ & $0.67-1.5 \times$ base case & {$[13,54-58,60]$} \\
\hline High-grade SIL regressing to well state, given regression occurs & 0.45 & $0.40-0.50$ & {$[13,54]$} \\
\hline $\begin{array}{l}\text { High-grade SIL regressing to previous HPV infection state, given } \\
\text { regression occurs }\end{array}$ & 0.05 & $0-0.10$ & {$[13,54]$} \\
\hline $\begin{array}{l}\text { High-grade SIL regressing to low-grade SIL, given regression } \\
\text { occurs }\end{array}$ & 0.50 & $0.40-0.60$ & {$[13,54]$} \\
\hline Developing cervical cancer from high-grade SIL & 0.038 & $0.03-0.06$ & {$[50-58]$} \\
\hline $\begin{array}{l}\text { Annual probability of developing symptoms with undiagnosed } \\
\text { cervical cancer }\end{array}$ & $0-1$ & & {$[13,54,61,62]$} \\
\hline Cervical cancer mortality & $0.0024-0.3334$ & $0.67-1.5 \times$ base case & $\begin{array}{l}\text { Estimated by the National Cancer } \\
\text { Registry of Taiwan }\end{array}$ \\
\hline \multicolumn{4}{|l|}{ Treatment variables } \\
\hline Treatment efficacy, given high-grade SIL, \% & 95 & $90-100$ & {$[13,63,64]$} \\
\hline $\begin{array}{l}\text { HPV infection persists, given effective treatment of high-grade } \\
\text { SIL, \% }\end{array}$ & 10 & $0-25$ & {$[13]$} \\
\hline \multicolumn{4}{|l|}{ Other variables } \\
\hline Discount rate, \% & 3 & $0-5$ & {$[43]$} \\
\hline Cycle length, year & 1 & & Assumed \\
\hline
\end{tabular}

*HPV denotes human papillomavirus; SIL, squamous intraepithelial lesion. All probabilities are annual unless otherwise noted. 
after diagnosis to reflect the severity of her disease and its effects on her quality of life. Follow-up of cervical cancer was assigned a moderate utility (0.95) once cancer went into remission. The chosen values responded to our expert criteria.

\section{Costs}

Only direct medical costs are considered in this study, which include the costs associated with the health care items reimbursed by the National Health Insurance (NHI) and the out-of-pocket payments such as outpatient registration fees, some drug charges or medical equipment expenses not covered by the NHI. Pap testing costs were US\$16 per test. The cost of treatment for SIL or cervical cancer was based on cost of initial colposcopy and biopsy, therapy, and subsequent follow-up. These costs were estimated by published literature of Tang et al. (2009) [41], expert opinions and official tariff lists of the NHI. The vaccination cost for three doses was assumed to be US\$364, which include the cost of the HPV vaccine itself, personnel, and administration. All costs were reported in 2009 US dollars with the exchange rate of $33 \mathrm{New}$ Taiwan dollars to US\$1.

\section{Vaccine characteristics}

We initially assumed the vaccine coverage rate to be $100 \%$ in the base case situation, i.e., all women received the required three doses within 1 year. Moreover, for our base case analysis, the vaccine was assumed to confer lifetime immunity against acquiring new infections by HPV16 and HPV-18. Because vaccine longevity is uncertain, the waning of vaccine protection over time becomes an important factor that could not be avoided. We evaluated the diverse waning scenarios that required booster shots with different compliance rates in sensitivity analysis. In the base case setting, vaccine efficacy against oncogenic types was estimated at $75 \%$. We examined a wide range of vaccine efficacy (from $50 \%$ to $100 \%$ ) to allow for further development of HPV vaccines and to deal with the possibility of lower coverage in Taiwan, where the prevalence of HPV-16 and HPV-18 infection in cervical cancer could be lower than $70 \%[9,42]$.

\section{Outcome measures}

We expressed our results in terms of the number of cervical cancer cases prevented and deaths avoided, as well as the life-years and quality-adjusted life-years (QALY) gained over a lifetime. The incremental cost-effectiveness ratio (ICER) was calculated as the accumulated total cost difference divided by the QALY gained per woman by adding vaccination to existing screening. The economic analysis adopted a 3\% annual discount rate for future costs and outcomes, which converts values that will occur in the future to their present value.

\section{Sensitivity analysis}

Sensitivity analyses were performed to account for important model assumptions and uncertainties including the vaccine characteristics, adherence to cervical screening, costs or health utilities for various conditions, parameters related to the natural history of disease, discount rate, etc; we also examined the impact of starting vaccination at different ages on the costeffectiveness ratio for HPV vaccine in sensitivity analysis. The ranges for costs were varied from minus $25 \%$ to plus $25 \%$ of the base case estimate. For clinical variables, our ranges for sensitivity analysis represented our judgment of the uncertainties and/or variations likely to be encountered in clinical practice, based on both the literature and the opinions of experts (Table 1).

\section{Results \\ Model validation}

Due to the main interests of this study and the certainty of data sources, cervical cancer incidence and mortality were chosen as primary endpoints for the model calibration process of matching the outputs in the current practice arm without vaccination of the model to observed cancer statistics. The model predicted the incidence rate for cervical cancer would be 21.1 per 100,000 females 12 or older, given the assumption that women would receive cervical screening with compliance rates of the current practice. Predicted cervical cancer incidence showed good correspondence with observed data from the National Cancer Registry of Taiwan between 2001 and 2005 that the overall incidence of cervical cancer cases was 22.7 per 100,000 females aged over 10 years (Figure 2). Moreover, the predicted HPV prevalence and cervical cancer mortality were also fit reasonably well to the observed epidemiological data, with the exception of a slightly lower mortality for ages over 65 . The predicted cervical cancer mortality would be 7.2 per 100,000 females 12 or older, while the observed overall cervical cancer mortality was 7.8 per 100,000 people for women aged over 10 years.

\section{Base case analysis}

In our base case analysis, the administration of HPV vaccine could reduce $73.3 \%$ of the total incident cervical cancer cases from 1,773 to 473 per 100,000 women and lessen $73.4 \%$ of cancer deaths from 710 to 189 per 100,000 women over the lifetime of the cohort of 12year-old girls. On average, their life expectancy would be improved by 4.9 days or 0.024 QALY. Adding an $\mathrm{HPV}$ vaccine was more expensive than current practice, with an overall increase in estimated lifetime discounted cost of US\$324. The incremental cost-effectiveness ratio based on this model was US\$13,674 per QALY gained (Table 2).

\section{Sensitivity analysis}

On the basis of our sensitivity analyses of various parameters, the model suggested that the ICER of adding vaccination strategy, as compared to the current 


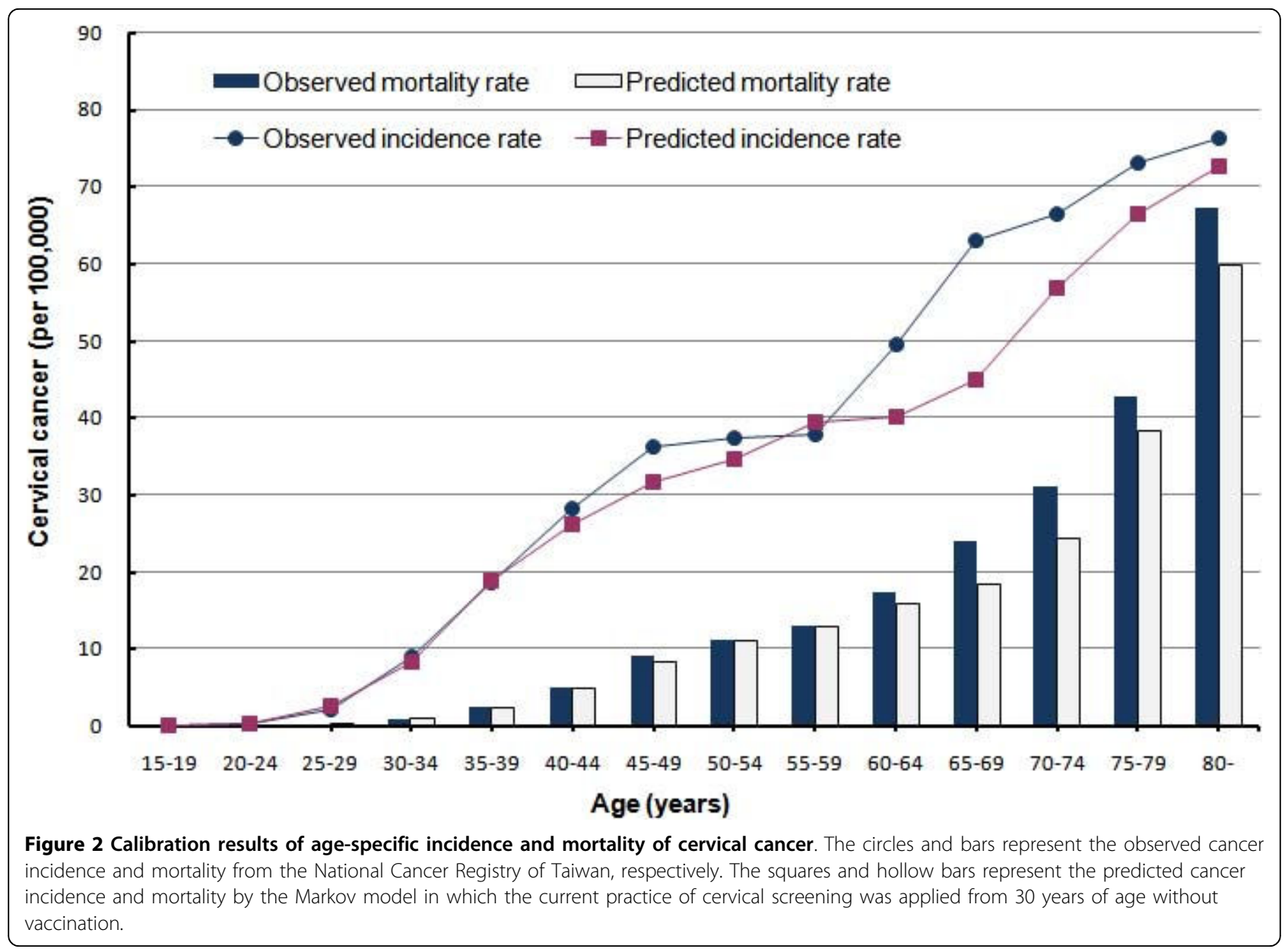

practice, is most sensitive to variations in discount rate, vaccine immunity longevity or booster frequency, incidence of high-risk HPV infection, compliance with Pap testing, vaccine efficacy and in quality of life for cervical cancer. Changes in these parameters could result in wider variations of the ICER, as depicted in Figure 3.

The incremental cost of vaccination would be usually less than US\$30,000/QALY relative to the current practice when the efficacy was greater than $37 \%$. If vaccination required a one-shot booster every 10 years, then the ICER would increase to US\$37,150/QALY which multiplied by 2.7 the base case outcome under lifelong immunization (Figure 4). The ICER would remain below US\$30,000/QALY if the interval of booster shots needed to maintain the immunity was over 13 years.

Vaccination cost-effectiveness, however, would be US $\$ 37,480 /$ QALY at a discounted rate of $5 \%$ since higher

Table 2 Health and economic outcomes of HPV vaccination, discounted

\begin{tabular}{|c|c|c|}
\hline Outcome & No vaccination & HPV vaccination \\
\hline Cost, US\$ & 129 & 453 \\
\hline Incremental cost, US\$ & & 324 \\
\hline Life expectancy, years & 28.830 & 28.844 \\
\hline Incremental life expectancy, days & & 4.9 \\
\hline Quality-adjusted life expectancy, years & 28.816 & 28.840 \\
\hline Incremental quality-adjusted life expectancy, days & & 8.7 \\
\hline \multicolumn{3}{|l|}{ Incremental cost-effectiveness ratio } \\
\hline US\$/life year & & 23939 \\
\hline US\$/quality-adjusted life year & & 13674 \\
\hline
\end{tabular}

HPV denotes human papillomavirus 


\section{Incremental cost-effectiveness of vaccination (US\$/QALY)}

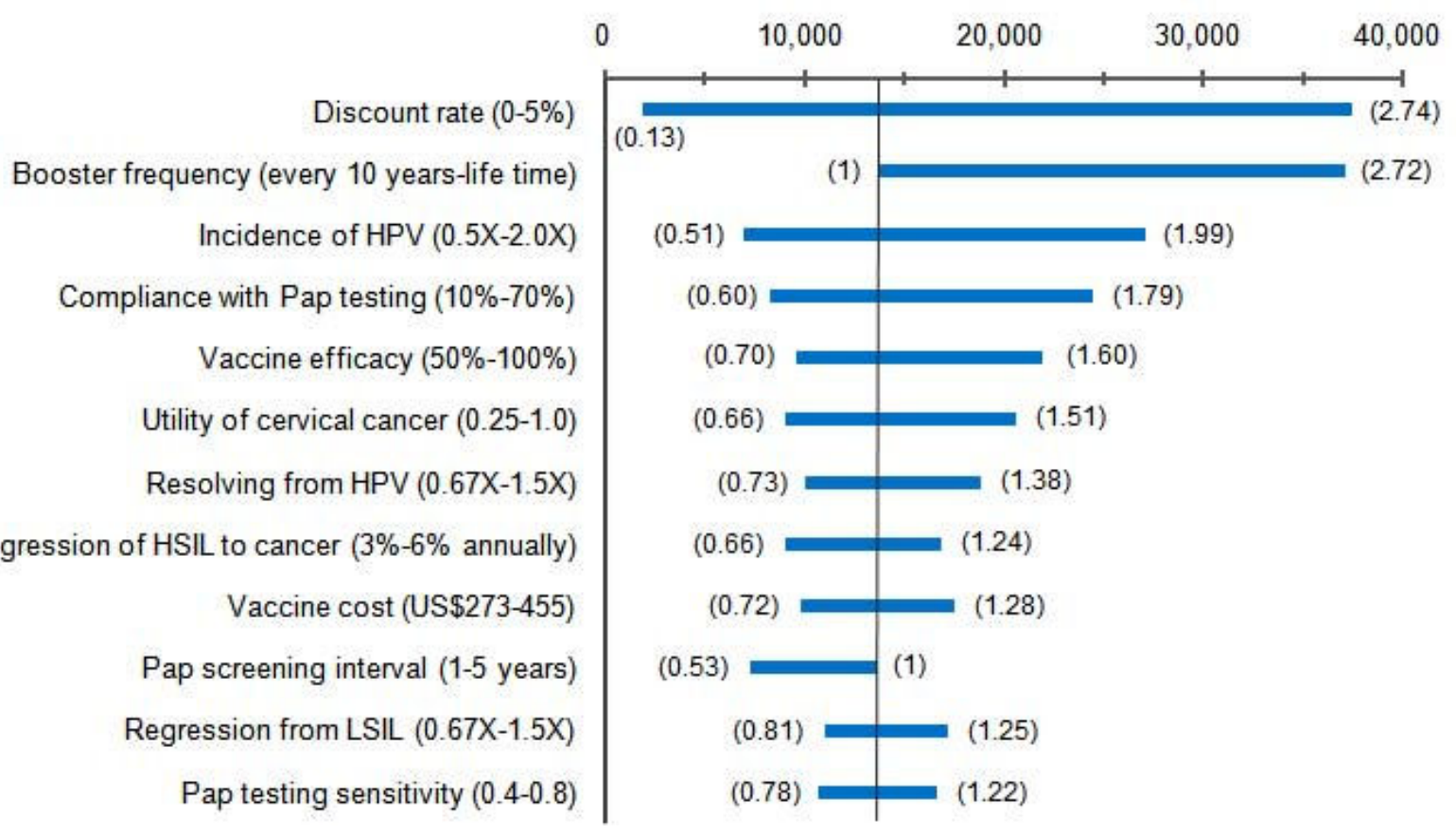

Figure 3 One-way sensitivity analyses on the incremental cost-effectiveness ratio (ICER). The range of input parameter for the sensitivity analysis is indicated in the parentheses on the left of the vertical axis. The vertical line represents the ICER under base case assumptions. The numbers in brackets alongside the bar represent the ratio between the maximum value (right) and the minimum one (left) in sensitivity analysis respectively over the base case ICER.

discount rates augment the relative weight of the initial vaccination costs.

If every woman in Taiwan obtained a Pap test every 3 years from the age of 30, the ICER of vaccination would slightly increase to US $\$ 17,199 /$ QALY.

\section{Discussion}

Our analysis demonstrated that under most assumptions, the prophylactic vaccination against HPV-16 and HPV-18 had an ICER between US\$7,000 and US $\$ 27,000$ per QALY gained in the vaccinated adolescent girls in Taiwan. The ICER would remain below US $\$ 30,000$ per QALY unless the vaccine efficacy declined to less than $38 \%$ or if the immunity waned and required booster shots every 10 years (Figure 4 ). If the vaccination cost could be reduced to below US\$277, then the HPV vaccination would cost less than US $\$ 10,000$ per QALY gained, indicating a potential for further enhancement of cost-effectiveness. Although there has been no domestic consensus on the threshold of the cost-effectiveness ratio for the National Health Insurance system to decide whether to reimburse a new medical intervention, the results of our analysis suggest that prophylactic vaccination against oncogenic HPV administered in preadolescent girls in Taiwan would be usually cost- effective based on the World Health Organization proposed criteria of 1-3 times the gross domestic product (GDP) per capita being cost-effective or less than GDP per capita being very cost-effective [43] since the GDP per capita of Taiwan was approximately US $\$ 17,082$ in 2008.

In addition to the discount rate, the duration of the vaccine immunity accounted for the most influential source of variations in the ICER of incorporating HPV vaccination within our investigation (Figure 3), which is consistent with other studies [27]. Compared to the previous studies mostly performed in Western countries [16,22-26], the HPV vaccination strategy in our study appeared to be attractive in terms of a lower ICER. However, this figure of cost-effectiveness in Taiwan could be largely owing to the high prevalence of HPV infection [6-9] and lower compliance rate with cervical cytological screening [1] that resulted in higher background incidence of cervical cancer, since we employed similar assumptions of time horizon, discount rate, vaccine efficacy and lifelong vaccine protection as most of those studies. For example, as the projected incidence of cervical cancer under the current screening practice in a study from the Netherlands [26] was lower than that in our study by 3.5 times and the vaccination costs were 


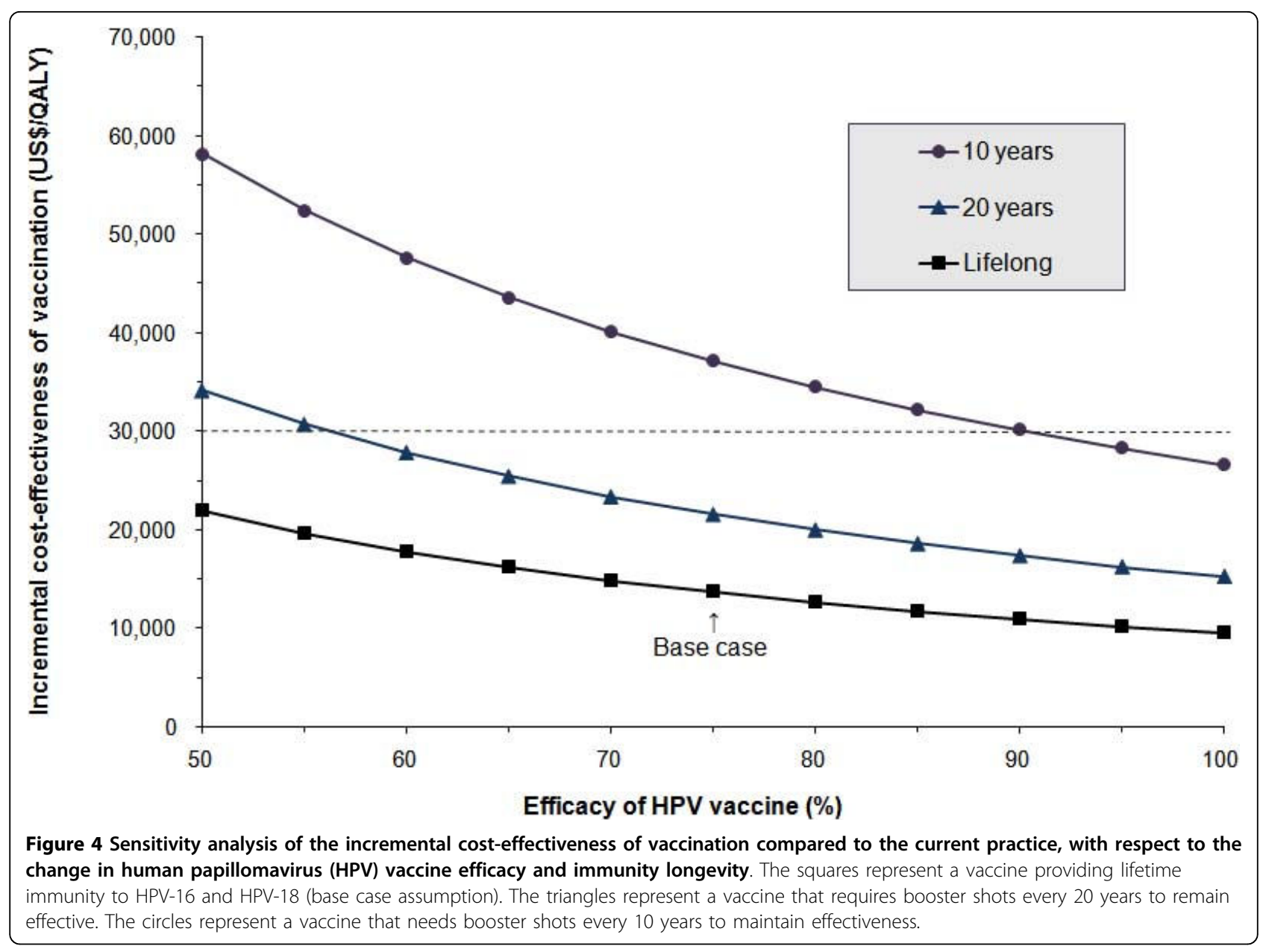

1.5 times more expensive, the ICER reported by them was much higher than the figure in our study (approximately 5.8 times).

Methodological differences may also account for variations in the results of different cost-effectiveness evaluations $[27,44]$. Although dynamic transmission model has been developed and applied [17,18,22,23,25,28], it generally requires investigators to make more assumptions on putting into parameter values related to viral transmission. As the sexual behavior in adolescents and young people in Taiwan may be different from that in western countries and the relevant data were insufficient, we took an alternative approach to adapt a simpler Markov model as previous studies [13,14,24], but more delicately adjusted the model with existing clinical and epidemiological data of cervical cancer in Taiwan. Our approach did not consider the herd immunity and the protection by HPV vaccination for genital warts or other HPV related cancers. Thus, we would underestimate the overall effectiveness of the vaccination program, which would generally make the cost-effectiveness of the HPV vaccine even more favorable if herd immunity or protection for other diseases existed $[21,45]$.

The relatively high risk level of invasive cervical cancer in Taiwan implies the urgency to improve the compliance rate of cervical screening to the early detection of SIL and cervical cancer, even though the ICER of prophylactic vaccination would rise accordingly because the marginal effectiveness of vaccination would be diminished as improvement in cytological screening would decrease the baseline incidence of invasive cervical cancer without adding HPV vaccination. Moreover, during the model calibration process, we discovered an upward trend of cervical cancer incidence by age that reflected inadequate compliance with cervical screening among older women, particularly those older than 60 years (Figure 2). Had the cervical screening compliance for older women improved to be comparable with those of younger women, the cumulative incident cases with cervical cancer would have decreased in both cohorts with or without vaccination, while the ICER of HPV vaccine would go up slightly to US $\$ 14,120$ per QALY gained. 
The impact of discounting is very complex in the context of HPV vaccination. As in any economic assessment of a preventive measure with later-onset effects, the initial intervention costs and the choice of discount rate have a significant influence on the cost-effectiveness results. In general, higher discount rates would make the prophylactic vaccination strategy seem less attractive, given that the costs of the intervention are paid immediately while the benefits come back many years later. Indeed, we found the undiscounted ICER of vaccination on 12-year-old girls was US $\$ 1,820$ per QALY gained, whereas the ICER significantly increased to US $\$ 37,480$ per discounted QALY gained at a discounted rate of $5 \%$.

There are limitations in this study. First, herd immunity effects were not taken into account in our model as discussed above. Second, women adherent to previous cervical screening tests tended to have better compliance with subsequent tests [1]. The preventive effects of screening could therefore be overestimated particularly for those at older ages, which in turn would underestimate the effectiveness of vaccination. Thus, the current ICER of HPV vaccine would be a conservative estimation, as the ICER should further decline if the actual compliance rates of cervical screening were adjusted with a lower coverage. Nonetheless, the conservative assessment for the ICER of HPV vaccine in our study, together with the results of other relevant research $[28,29]$, would increase the credibility of the cost-effectiveness for a prophylactic HPV vaccination program in Taiwan.

\section{Conclusions}

Our analysis suggested that vaccination of adolescent girls with an HPV vaccine seems to be cost-effective in Taiwan where the HPV infection rate and the incidence as well as the mortality of cervical cancer are relatively higher than those in other developed countries. Although there are still some uncertainties regarding the HPV vaccine and cervical cytological screening, our estimation of the cost-effectiveness for a prophylactic vaccine against high-risk HPV, however, appears to be robust. We have demonstrated that the ICER would usually fall below US $\$ 30,000$ per QALY gained under most assumptions, which also covers a wide range of vaccination strategies and vaccine characteristics. Even in the case of favorable cost-effectiveness ratio of prophylactic vaccination against oncogenic HPV, there is still room for improvement of the compliance with Pap screening tests in Taiwan, especially for older women, because vaccination should not yet be regarded as the substitute for cytological screening. It calls attention to the importance of continuing research that investigates primary and secondary preventive measures against cervical cancer.

\section{Acknowledgements}

This study was supported by a grant from the Department of Health, Executive Yuan of Taiwan to establish the National Clinical Trial and Research Center at the National Taiwan University Hospital (DOH97-TD-B111-001 and DOH98-TD-B-111-001). Its contents are solely the responsibility of the authors and do not necessarily represent the official views of the Department of Health.

The authors are grateful to Chang-Chuan Chan, Pau-Chung Chen, Yue-Leon Guo and Jin-Tan Liu for their important recommendations. We would also like to acknowledge the peer-reviewers, Anna Garcia-Altes and Jaume PuigJunoy, for their valuable comments and critiques.

\section{Author details}

${ }^{1}$ National Clinical Trial and Research Center, National Taiwan University Hospital, Taipei, Taiwan. ${ }^{2}$ Institute of Occupational Medicine and Industrial Hygiene, College of Public Health, National Taiwan University, Taipei, Taiwan. ${ }^{3}$ Department of Pediatrics, National Taiwan University Hospital, Taipei, Taiwan. ${ }^{4}$ Department of Obstetrics Gynecology, National Taiwan University Hospital and College of Medicine, National Taiwan University, Taipei, Taiwan. ${ }^{5}$ Departments of Internal Medicine and Environmental and Occupational Medicine, National Taiwan University Hospital, Taipei, Taiwan.

\section{Authors' contributions}

All of the authors formulated the research question and design of the study. $\mathrm{P}-\mathrm{HL}$ extracted the data and carried out the analyses. F-CH, P-IL, S-NC and JDW provided intellectual input into the analyses and/or interpretation of data. C-WH participated in the analyses. P-HL and J-DW prepared the first draft of the manuscript. F-CH, P-IL, and S-NC provided content expertise and contributed to the final version of the manuscript. All authors have read and approved the submission of the manuscript to BMC Health Services Research in its present form.

\section{Competing interests}

S-NC has served on advisory boards for GlaxoSmithKline, and has been the Principal Investigator at National Taiwan University Hospital for GlaxoSmithKline clinical trial (HPV-008 Study) since 2004 up to now. All the other authors declare that they have no interests which might be perceived as giving rise to any form of bias or conflict of interest.

Received: 9 September 2009

Accepted: 11 January 2010 Published: 11 January 2010

\section{References}

1. Pap Smear Screening Registry System Annual Report, 2007 Taipei: Bureau of Health Promotion, Department of Health, Taiwan 2008.

2. Tay SK, Ngan HY, Chu TY, Cheung AN, Tay EH: Epidemiology of human papillomavirus infection and cervical cancer and future perspectives in Hong Kong, Singapore and Taiwan. Vaccine 2008, 26(Suppl 12):M60-70.

3. Taiwan Cancer Registry, Department of Health (Taiwan): Cancer Incidence and Mortality Rates in Taiwan.http://crs.cph.ntu.edu.tw/uploadimages/ Leading_10.pdf.

4. Walboomers JM, Jacobs MV, Manos MM, Bosch FX, Kummer JA, Shah KV, Snijders PJ, Peto J, Meijer CJ, Munoz N: Human papillomavirus is a necessary cause of invasive cervical cancer worldwide. J Pathol 1999, 189(1):12-19.

5. Franco EL, Rohan TE, Villa LL: Epidemiologic evidence and human papillomavirus infection as a necessary cause of cervical cancer. J Natl Cancer Inst 1999, 91(6):506-511.

6. Jeng CJ, Phdl, Ko ML, Ling QD, Shen J, Lin HW, Tzeng CR, Ho CM, Chien TY, Chen SC: Prevalence of cervical human papillomavirus in Taiwanese women. Clin Invest Med 2005, 28(5):261-266.

7. Lin H, Ma YY, Moh JS, Ou YC, Shen SY, ChangChien CC: High prevalence of genital human papillomavirus type 52 and 58 infection in women attending gynecologic practitioners in South Taiwan. Gynecol Oncol 2006, 101(1):40-45.

8. Chao A, Hsu KH, Lai CH, Huang HJ, Hsueh S, Lin SR, Jung SM, Chao FY, Huang SL, Huang CC, et al: Cervical cancer screening program integrating Pap smear and HPV DNA testing: a population-based study. Int J Cancer 2008, 122(12):2835-2841.

9. Ding DC, Hsu HC, Huang RL, Lai HC, Lin CY, Yu MH, Chu TY: Type-specific distribution of HPV along the full spectrum of cervical carcinogenesis in 
Taiwan: an indication of viral oncogenic potential. Eur J Obstet Gynecol Reprod Biol 2008, 140(2):245-251.

10. Paavonen J, Jenkins D, Bosch FX, Naud P, Salmeron J, Wheeler CM, Chow SN, Apter DL, Kitchener HC, Castellsague X, et al: Efficacy of a prophylactic adjuvanted bivalent L1 virus-like-particle vaccine against infection with human papillomavirus types 16 and 18 in young women: an interim analysis of a phase III double-blind, randomised controlled trial. Lancet 2007, 369(9580):2161-2170.

11. Paavonen J, Naud P, Salmeron J, Wheeler CM, Chow SN, Apter D, Kitchener H, Castellsague X, Teixeira JC, Skinner SR, et al: Efficacy of human papillomavirus (HPV)-16/18 AS04-adjuvanted vaccine against cervical infection and precancer caused by oncogenic HPV types (PATRICIA): final analysis of a double-blind, randomised study in young women. Lancet 2009, 374(9686):301-314.

12. Villa LL, Costa RL, Petta CA, Andrade RP, Ault KA, Giuliano AR, Wheeler CM Koutsky LA, Malm C, Lehtinen $M$, et al: Prophylactic quadrivalent human papillomavirus (types $6,11,16$, and 18) L1 virus-like particle vaccine in young women: a randomised double-blind placebo-controlled multicentre phase II efficacy trial. Lancet Oncol 2005, 6(5):271-278.

13. Sanders GD, Taira AV: Cost-effectiveness of a potential vaccine for human papillomavirus. Emerg Infect Dis 2003, 9(1):37-48.

14. Goldie SJ, Kohli M, Grima D, Weinstein MC, Wright TC, Bosch FX, Franco E: Projected clinical benefits and cost-effectiveness of a human papillomavirus 16/18 vaccine. J Natl Cancer Inst 2004, 96(8):604-615.

15. Taira AV, Neukermans CP, Sanders GD: Evaluating human papillomavirus vaccination programs. Emerg Infect Dis 2004, 10(11):1915-1923.

16. Brisson M, Velde Van de N, De Wals P, Boily MC: The potential costeffectiveness of prophylactic human papillomavirus vaccines in Canada. Vaccine 2007, 25(29):5399-5408.

17. Elbasha EH, Dasbach EJ, Insinga RP: Model for assessing human papillomavirus vaccination strategies. Emerg Infect Dis 2007, 13(1):28-41.

18. Insinga RP, Dasbach EJ, Elbasha EH, Puig A, Reynales-Shigematsu LM: Costeffectiveness of quadrivalent human papillomavirus (HPV) vaccination in Mexico: a transmission dynamic model-based evaluation. Vaccine 2007, 26(1):128-139.

19. Kulasingam S, Connelly L, Conway E, Hocking JS, Myers E, Regan DG, Roder D, Ross J, Wain G: A cost-effectiveness analysis of adding a human papillomavirus vaccine to the Australian National Cervical Cancer Screening Program. Sex Health 2007, 4(3):165-175.

20. Bergeron C, Largeron N, McAllister R, Mathevet $P$, Remy V: Costeffectiveness analysis of the introduction of a quadrivalent human papillomavirus vaccine in France. Int J Technol Assess Health Care 2008, 24(1):10-19.

21. Chesson HW, Ekwueme DU, Saraiya M, Markowitz LE: Cost-effectiveness of human papillomavirus vaccination in the United States. Emerg Infect Dis 2008, 14(2):244-251.

22. Jit $\mathrm{M}$, Choi YH, Edmunds WJ: Economic evaluation of human papillomavirus vaccination in the United Kingdom. BMJ 2008, 337:a769.

23. Kim JJ, Goldie SJ: Health and economic implications of HPV vaccination in the United States. N Engl J Med 2008, 359(8):821-832.

24. Kulasingam SL, Benard S, Barnabas RV, Largeron N, Myers ER: Adding a quadrivalent human papillomavirus vaccine to the UK cervical cancer screening programme: A cost-effectiveness analysis. Cost Eff Resour Alloc 2008, 6:4.

25. Ginsberg GM, Fisher M, Ben-Shahar I, Bornstein J: Cost-utility analysis of vaccination against HPV in Israel. Vaccine 2007, 25(37-38):6677-6691

26. de Kok IM, van Ballegooijen M, Habbema JD: Cost-effectiveness analysis of human papillomavirus vaccination in the Netherlands. J Natl Cancer Inst 2009, 101(15):1083-1092.

27. Puig-Junoy J, Lopez-Valcarcel BG: Economic evaluations of massive HPV vaccination: within-study and between study variations in incremental cost per QALY gained. Prev Med 2009, 48(5):444-448.

28. Dasbach EJ, Insinga RP, Yang YC, Pwu RF, Lac C, Elbasha EH: The costeffectiveness of a quadrivalent human papillomavirus vaccine in Taiwan. Asian Pac J Cancer Prev 2008, 9(3):459-466.

29. Debicki D, Ferko N, Demarteau N, Gallivan S, Bauch C, Anonychuk A, Mantovani L, Capri S, Chou CY, Standaert B, et al: Comparison of detailed and succinct cohort modelling approaches in a multi-regional evaluation of cervical cancer vaccination. Vaccine 2008, 26(Suppl 5):F16-28.

30. Sonnenberg FA, Beck JR: Markov models in medical decision making: a practical guide. Med Decis Making 1993, 13(4):322-338.
31. Cuzick J, Szarewski A, Terry G, Ho L, Hanby A, Maddox P, Anderson M, Kocjan G, Steele ST, Guillebaud J: Human papillomavirus testing in primary cervical screening. Lancet 1995, 345(8964):1533-1536.

32. Fahey MT, Irwig L, Macaskill P: Meta-analysis of Pap test accuracy. Am J Epidemiol 1995, 141(7):680-689.

33. Goodman MT, Shvetsov YB, McDuffie K, Wilkens LR, Zhu X, Thompson PJ, Ning L, Killeen J, Kamemoto L, Hernandez BY: Prevalence, acquisition, and clearance of cervical human papillomavirus infection among women with normal cytology: Hawaii Human Papillomavirus Cohort Study. Cancer Res 2008, 68(21):8813-8824.

34. Rodriguez AC, Burk R, Herrero R, Hildesheim A, Bratti C, Sherman ME, Solomon D, Guillen D, Alfaro M, Viscidi R, et al: The natural history of human papillomavirus infection and cervical intraepithelial neoplasia among young women in the Guanacaste cohort shortly after initiation of sexual life. Sex Transm Dis 2007, 34(7):494-502.

35. Moscicki AB, Shiboski S, Broering J, Powell K, Clayton L, Jay N, Darragh TM, Brescia R, Kanowitz S, Miller SB, et al: The natural history of human papillomavirus infection as measured by repeated DNA testing in adolescent and young women. J Pediatr 1998, 132(2):277-284.

36. Ho GY, Bierman R, Beardsley L, Chang CJ, Burk RD: Natural history of cervicovaginal papillomavirus infection in young women. $N$ Engl J Med 1998, 338(7):423-428.

37. Hildesheim A, Schiffman MH, Gravitt PE, Glass AG, Greer CE, Zhang T, Scott DR, Rush BB, Lawler P, Sherman ME, et al: Persistence of typespecific human papillomavirus infection among cytologically normal women. J Infect Dis 1994, 169(2):235-240.

38. Franco EL, Villa LL, Sobrinho JP, Prado JM, Rousseau MC, Desy M, Rohan TE: Epidemiology of acquisition and clearance of cervical human papillomavirus infection in women from a high-risk area for cervical cancer. J Infect Dis 1999, 180(5):1415-1423.

39. Koong SL, Yen AM, Chen TH: Efficacy and cost-effectiveness of nationwide cervical cancer screening in Taiwan. J Med Screen 2006, 13(Suppl 1):S44-47.

40. Stratton KR, Durch JS, Lawrence RS, Eds: Vaccines for the 21st Century: A Tool for Decisionmaking Washington: National Academy Press 2000.

41. Tang CH, Pwu RF, Tsai IC, Wang HI, You SL, Chen CA, Scuffham PA, Hsieh CY, Chou CY, Lin SR, et al: Costs of cervical cancer and precancerous lesions treatment in a publicly financed health care system. Arch Gynecol Obstet.

42. Liaw KL, Hsing AW, Schiffman MH, You SL, Zhang T, Burk R, Chen CJ: Human papillomavirus types 52 and 58 are prevalent in cervical cancer from Chinese women. Int J Cancer 1997, 73(5):775-776.

43. Making choices in health: WHO guide to cost-effectiveness analysis Geneva: World Health Organisation 2003.

44. Newall AT, Beutels P. Wood JG, Edmunds WJ, Maclntyre CR. Costeffectiveness analyses of human papillomavirus vaccination. Lancet Infect Dis 2007, 7(4):289-296.

45. Brisson M, Edmunds WJ: Economic evaluation of vaccination programs: the impact of herd-immunity. Med Decis Making 2003, 23(1):76-82.

46. Harper DM, Franco EL, Wheeler CM, Moscicki AB, Romanowski B, RoteliMartins CM, Jenkins D, Schuind A, Costa Clemens SA, Dubin G: Sustained efficacy up to 4.5 years of a bivalent L1 virus-like particle vaccine against human papillomavirus types 16 and 18: follow-up from a randomised control trial. Lancet 2006, 367(9518):1247-1255.

47. Villa LL, Costa RL, Petta CA, Andrade RP, Paavonen J, Iversen OE, Olsson SE, Hoye J, Steinwall M, Riis-Johannessen G, et al: High sustained efficacy of a prophylactic quadrivalent human papillomavirus types 6/11/16/18 L1 virus-like particle vaccine through 5 years of follow-up. Br J Cancer 2006, 95(11):1459-1466.

48. Quadrivalent vaccine against human papillomavirus to prevent highgrade cervical lesions. N Engl J Med 2007, 356(19):1915-1927.

49. Markowitz LE, Dunne EF, Saraiya M, Lawson HW, Chesson H, Unger ER: Quadrivalent Human Papillomavirus Vaccine: Recommendations of the Advisory Committee on Immunization Practices (ACIP). MMWR Recomm Rep 2007, 56(RR-2):1-24.

50. Liaw KL, Hsing AW, Chen CJ, Schiffman MH, Zhang TY, Hsieh CY, Greer CE, You SL, Huang TW, Wu TC, et al: Human papillomavirus and cervical neoplasia: a case-control study in Taiwan. Int J Cancer 1995, 62(5):565-571.

51. Liaw KL, Glass AG, Manos MM, Greer CE, Scott DR, Sherman M, Burk RD, Kurman RJ, Wacholder S, Rush BB, et al: Detection of human papillomavirus DNA in cytologically normal women and subsequent 
cervical squamous intraepithelial lesions. J Natl Cancer Inst 1999, 91(11):954-960.

52. Chen CA, Liu CY, Chou HH, Chou CY, Ho CM, Twu NF, Kan YY, Chuang MH, Chu TY, Hsieh CY: The distribution and differential risks of human papillomavirus genotypes in cervical preinvasive lesions: A Taiwan Cooperative Oncologic Group Study. Int I Gynecol Cancer 2006, 16(5):1801-1808.

53. Herrero R, Castle PE, Schiffman M, Bratti MC, Hildesheim A, Morales J, Alfaro M, Sherman ME, Wacholder S, Chen S, et al: Epidemiologic profile of type-specific human papillomavirus infection and cervical neoplasia in Guanacaste, Costa Rica. J Infect Dis 2005, 191(11):1796-1807.

54. Myers ER, McCrory DC, Nanda K, Bastian L, Matchar DB: Mathematical model for the natural history of human papillomavirus infection and cervical carcinogenesis. Am J Epidemiol 2000, 151(12):1158-1171.

55. Ostor AG: Natural history of cervical intraepithelial neoplasia: a critical review. Int I Gynecol Pathol 1993, 12(2):186-192.

56. Melnikow J, Nuovo J, Willan AR, Chan BK, Howell LP: Natural history of cervical squamous intraepithelial lesions: a meta-analysis. Obstet Gynecol 1998, 92(4 Pt 2):727-735.

57. Holowaty $P$, Miller $A B$, Rohan $T$, To $T$ : Natural history of dysplasia of the uterine cervix. J Natl Cancer Inst 1999, 91(3):252-258.

58. Schlecht NF, Platt RW, Duarte-Franco E, Costa MC, Sobrinho JP, Prado JC, Ferenczy A, Rohan TE, Villa LL, Franco EL: Human papillomavirus infection and time to progression and regression of cervical intraepithelial neoplasia. J Natl Cancer Inst 2003, 95(17):1336-1343.

59. Moscicki AB, Hills N, Shiboski S, Powell K, Jay N, Hanson E, Miller S, Clayton L, Farhat S, Broering J, et al: Risks for incident human papillomavirus infection and low-grade squamous intraepithelial lesion development in young females. JAMA 2001, 285(23):2995-3002.

60. Nobbenhuis MA, Helmerhorst TJ, Brule van den AJ, Rozendaal L, Voorhorst FJ, Bezemer PD, Verheijen RH, Meijer CJ: Cytological regression and clearance of high-risk human papillomavirus in women with an abnormal cervical smear. Lancet 2001, 358(9295):1782-1783.

61. Janerich DT, Hadjimichael O, Schwartz PE, Lowell DM, Meigs JW, Merino MJ, Flannery JT, Polednak AP: The screening histories of women with invasive cervical cancer, Connecticut. Am J Public Health 1995, 85(6):791-794.

62. Schwartz PE, Hadjimichael O, Lowell DM, Merino MJ, Janerich D: Rapidly progressive cervical cancer: the Connecticut experience. Am J Obstet Gynecol 1996, 175(4 Pt 2):1105-1109.

63. Oyesanya $\mathrm{OA}$, Amerasinghe $\mathrm{CN}$, Manning EA: Outpatient excisional management of cervical intraepithelial neoplasia. A prospective, randomized comparison between loop diathermy excision and laser excisional conization. Am J Obstet Gynecol 1993, 168(2):485-488.

64. Wright TC Jr, Koulos J, Schnoll F, Swanbeck J, Ellerbrock TV, Chiasson MA, Richart RM: Cervical intraepithelial neoplasia in women infected with the human immunodeficiency virus: outcome after loop electrosurgical excision. Gynecol Oncol 1994, 55(2):253-258.

\section{Pre-publication history}

The pre-publication history for this paper can be accessed here:http://www. biomedcentral.com/1472-6963/10/11/prepub

\section{Publish with Bio Med Central and every scientist can read your work free of charge}

"BioMed Central will be the most significant development for disseminating the results of biomedical research in our lifetime. " Sir Paul Nurse, Cancer Research UK

Your research papers will be:

- available free of charge to the entire biomedical community

- peer reviewed and published immediately upon acceptance

- cited in PubMed and archived on PubMed Central

- yours - you keep the copyright
BioMedcentral 